\title{
Primary Care Teams: Past, Present and Future
}

\author{
Erin P. Fraber, PhD, MPP
}

(J Am Board Fam Med 2020;33:495-498.)

Evidence is mixed on the effect of value-based payment models on access, quality, and care. ${ }^{1-3}$ One reason may be that while a great deal of attention has been paid to redesigning care delivery and payment models, less focus has centered on redesigning the workforce to deliver team-based care in new models of care. ${ }^{4}$ Bodenheimer ${ }^{5}$ suggests that the survival of primary care hinges on creating teams that share the care with well-trained and empowered health professionals who can take on functions that do not require a physician. Such structural changes to primary care require retraining physicians and other providers to more effectively function in teams, remapping workflows, and redesigning care to allow for more collaboration between physicians and other health care professionals. ${ }^{6-9}$ Despite the growing body of research on the evolving roles of medical assistants, ${ }^{10,11}$ nurses (RNs), ${ }^{12,13}$ social workers, ${ }^{14}$ pharmacists, ${ }^{15}$ nurse practitioners (NPs), and physician assistants (PAs), ${ }^{16}$ we lack a good understanding of different team configurations in primary care practices.

In this issue, Jabbarpour et $\mathrm{al}^{17}$ use data from a question on the American Board of Family Medicine (ABFM) examination application asking active family physicians about the types of health professionals with whom they practiced between 2014 to 2018 . With a $100 \%$ response rate of the approximately $10 \%$ of $\mathrm{ABFM}$ certified physicians who take the examination each year, the generalizability of these data to the underlying population of board-certified family physicians' (FPs') practices in the United States is strong.

From the University of North Carolina at Chapel Hill.

Corresponding author: Erin P. Fraher, PhD, MPP, Department of Family Medicine and Cecil G. Sheps Center for Health Services Research, The University of North Carolina at Chapel Hill, Chapel Hill, NC 27599 (E-mail: fraher@schsr.unc.edu).
Slightly more than half (55.9\%) of family physicians reported practicing with NPs in 2018, but there was no discernible trend over the period. Given NPs' rapid growth in primary care practices, the lack of growth in FPs working with NPs is surprising. ${ }^{18}$ Despite changing the question in 2017 to include the word, "collaboratively," ["Which of the following types of health professionals work collaboratively with you at your principal site?"], the authors note that is unclear whether respondents who indicated they were working with NPs were practicing alongside NPs or providing team-based care to a common panel of patients.

The percentage of family physicians practicing with RNs increased from $47 \%$ in 2014 to nearly $54 \%$ in 2018, suggesting that practices are increasingly working with RNs where they may be triaging patients and acting as chronic care managers, care coordinators, and health coaches for patients with uncomplicated diabetes, hypertension, hyperlipidemia. ${ }^{12}$ Slightly more than $40 \%$ of FPs reported consistently working with PAs between 2014 and 2018. The percentage working with clinical pharmacists, behavior specialists and social workers increased 5 percentage points, from about $21 \%$ to $26 \%$. The most striking finding in the analysis is that the percentage of family physicians who reported working with licensed practical nurses (LPNs) increased from $34.5 \%$ in 2014 to $49.3 \%$ in 2018.

\section{Expanding Roles for Social Workers in Primary Care}

Social workers play important roles in providing integrated behavioral health care in primary care settings, assessing and screening patients, providing behavioral health interventions, and connecting clients with resources to address food insecurity, transportation, and other factors that affect behavioral 
and mental health. ${ }^{14,19}$ Given the emergence of integrated behavioral health and primary care models, it is surprising that not more FPs reported working with social workers and other behavioral health specialists. However, the data are consistent with a study by Lombardi et $\mathrm{a}^{20}$ that used national provider identifier data to identify colocation patterns of social workers and primary care physicians. That study found that $25.8 \%$ of social workers were colocated with a family physician and that colocation was more common in larger practices (employing over 25 PCPs) and less common in rural settings. Given that embedding social workers in primary care settings improves health outcomes, ${ }^{14}$ the percentage of FPs who report working with social workers is likely to increase as public and private payers shift toward value-based payment models that emphasize addressing the "upstream" social determinants of health.

\section{LPNs \& the Shift Toward Ambulatory Care and Value- Based Payment Models}

In 2019, 400,000 new jobs were created, one quarter $(102,000)$ of these jobs were in hospitals and about two thirds $(269,000)$ were in ambulatory settings such as outpatient care settings, home health and physician offices. ${ }^{21}$ Care is shifting from more expensive acute settings to less expensive ambulatory care settings and as care shifts, the number of FPs who report working with LPNs is likely to continue to increase.

Since the 1980s, LPNs have been shifting from hospitals into long-term care and community-based settings. ${ }^{22}$ LPNs are vital to skilled nursing facilities and other extended-care facilities. ${ }^{23}$ Coffmanet $\mathrm{al}^{24}$ found that between 2008 and 2013, home health agencies had the largest increase in LPN employment in the United States. More recent data from North Carolina suggest that while employment in home health continued to grow, between 2015 and 2018 , jobs in nursing homes, extended care facilities, and assisted living facilities declined by $6 \%$ (Figure 1). Hospital employment declined by an even greater amount-21\%-and LPN employment in ambulatory care grew by $47 \%$. While representative of just 1 state, these data represent a full census of actively practicing LPNs in each year and are consistent with the findings of Jabbarpour et $\mathrm{al}^{17}$ of more FPs working with LPNs in outpatient care.
As health systems, insurers, and practices adopt risk- and value-based payment models that seek to reduce hospital admissions and readmissions, more FPs may also find themselves working with physical therapists and occupational therapists. Stroke patients who receive outpatient therapy in the first 30 days after discharge home are less likely to be readmitted to the hospital. ${ }^{25}$

\section{Factors Affecting Team Composition}

In a study of evolving health workforce roles in 17 accountable care organizations, Sandberg et $\mathrm{al}^{26}$ found that there is no "single model" of care, distribution of tasks, or provider-to-patient ratios that worked equally well for all sites. Instead, organizations tailor the composition of their teams according to the complexity and health care needs of their patient population and around provider availability and preferences. Team composition is also dependent on the size of practice with larger practices able to use a more diverse team. ${ }^{27}$ Health system affiliation also matters as systems have more resources to hire nonbilling team members. However, building teams in academic teaching practices may be more challenging than in nonteaching practices ${ }^{5}$ because FPs in these practices tend to spend less time in clinic due to research and teaching obligations so team composition is not as stable or continuous.

A lack of understanding of other health professionals' training, qualifications, and competence can act as a barrier to optimal deployment of health professionals on teams. A study of communitybased family medicine practices in $2001^{28}$ found that interprofessional practice with RNs, LPNs, certified medical assistants and other staff was determined by physician expectations rather than the education, training or licensure of team members. This suggests opportunities for more deliberate staffing models that better deploy RNs and other patient care staff in primary care settings. This may be challenging as Leach et $\mathrm{al}^{29}$ found that primary care team structures are often not the result of an explicit plan but evolve organically. They are often shaped by provider preferences and factors outside the practices' control such as lack of reimbursement for staff who do not bill for their services, scope of practice restrictions, ${ }^{30}$ physicians lacking trust in the abilities of other team members, ${ }^{7}$ and the need for a culture change from "I" to "we." 31 
Figure 1. Licensed Practical Nurse Employment Settings, North Carolina, 2014-2018.

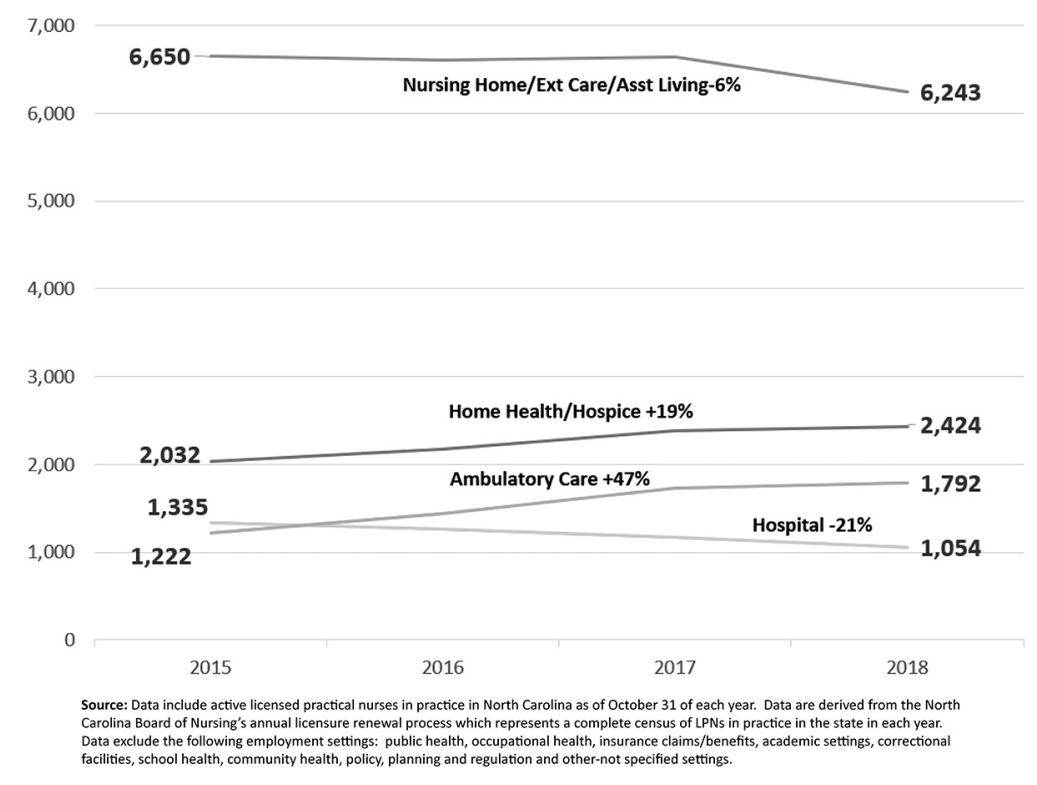

Ultimately, the ability to share care across interprofessional teams may be critical for the survival of primary care along with the well-being of the FP workforce. ${ }^{32}$ A recent study of primary care physicians found that practices' ability to "address patients' social needs mitigates burnout symptoms." ${ }^{33}$ Helfich et $\mathrm{al}^{34}$ found lower burnout in medical home models that were appropriately staffed, emphasized participatory decision making, and increased the proportion of time team members spend working at the top of their competency level. While these findings suggest that team-based models of care can reduce burnout, workflows must go beyond task delegation. A study of primary care providers and RNs in Veterans Affairs primary care clinics found that increased staffing and enhanced roles for RNs reduced burnout for primary care physicians but also increased burnout for RNs. ${ }^{35}$

Future research on teams in family medicine practices needs to delve beneath the numbers to investigate how evolving payment models, such as capitation and risk-based models of care, affect not only the skill mix but also the content of care provided by different health professionals on primary care teams. Recent changes to reimbursement for telehealth, if made permanent, will have dramatic changes on workflows and roles. The challenge to redesign primary care is not simply one of determining how to reconfigure the existing workforce, we must also develop best practices in training residents on interprofessional teams so that an understanding of the role and value of other team members' roles imprints early on their practice.

To see this article online, please go to: bttp://jabfm.org/content/ 33/4/495.full.

\section{References}

1. Sinaiko AD, Landrum MB, Meyers DJ, et al. Synthesis of research on patient-centered medical homes brings systematic differences into relief. Health Aff (Millwood) 2017;36:500-8.

2. McWilliams JM. Savings from ACOs-Building on early success. Ann Intern Med 2016;165:873-5.

3. McWilliams JM, Chernew ME, Landon BE. Medicare ACO program savings not tied to preventable hospitalizations or concentrated among high-risk patients. Health Aff (Millwood) 2017;36: 2085-93.

4. Fraher E, Machta R, Halladay J. The workforce transformations needed to staff value-based models of care. Carolina Center for Health Workforce Research. November 2015.

5. Bodenheimer T. Anatomy and physiology of primary care teams. JAMA Intern Med 2019;179:61-2.

6. Bodenheimer T, Grumbach K, Berenson RA. A lifeline for primary care. N Engl J Med 2009;360: 2693-6.

7. Ladden MD, Bodenheimer T, Fishman NW, et al. The emerging primary care workforce: preliminary observations from the primary care team: learning from effective ambulatory practices project. Acad Med 2013;88:1830-4. 
8. Bodenheimer T, Pham HH. Primary care: current problems and proposed solutions. Health Aff (Project Hope) 2010;29:799-805.

9. Bodenheimer T, Chen E, Bennett HD. Confronting the growing burden of chronic disease: can the U.S. health care workforce do the job? Health Aff (Project Hope) 2009;28:64-74.

10. Chapman SA, Blash LK. New roles for medical assistants in innovative primary care practices. Health Serv Res 2017;52:383-406.

11. Bodenheimer T, Willard-Grace R, Ghorob A. Expanding the roles of medical assistants: who does what in primary care? JAMA Intern Med 2014;174: 1025-6.

12. Bodenheimer T, Bauer L. Rethinking the primary care workforce-An expanded role for nurses. $\mathrm{N}$ Engl J Med 2016;375:1015-7.

13. Bauer L, Bodenheimer T. Expanded roles of registered nurses in primary care delivery of the future. Nursing outlook 2017;65:624-32.

14. Fraser M, Lombardi B, Wu S, Zerden L, Richman E, Fraher E. Social work in integrated primary care: a systematic review. J Soc Social Work Res 2018;9: 175-215.

15. Isasi FK. The expanding role of pharmacists in a transformed health care system. national governors association. January 2015. Available from: https:// www.nga.org/center/publications/health/the-expandingrole-of-pharmacists-in-a-transformed-health-caresystem/.

16. Altschuler J, Margolius D, Bodenheimer T, Grumbach K. Estimating a reasonable patient panel size for primary care physicians with team-based task delegation. Ann Fam Med 2012;10:396-400.

17. Jabbarpour Y, Jetty A, Dai M, Magill M, Bazemore A. The evolving family medicine team. J Am Board Fam Med 2020;33:xxx-xxx.

18. Barnes H, Richards MR, McHugh MD, Martsolf G. Rural and nonrural primary care physician practices increasingly rely on nurse practitioners. Health Aff (Project Hope) 2018;37:908-14.

19. Stanhope V, Videka L, Thorning H, McKay M. Moving toward integrated health: an opportunity for social work. Soc Work Health Care 2015; 54:383-407.

20. Lombardi BM, Zerden LS, Richman EL. Where are social workers co-located with primary care physicians? Soc Work Health Care 2019;58: 885-98.

21. Insights from monthly employment data through December 2019. Altarum Center for Value in Health Care. January 17, 2020. Available from: https:// altarum.org/sites/default/files/uploaded-publicationfiles/January\%202020\%20Labor\%20Brief.pdf.
22. Buerhaus PI, Staiger DO. Managed care and the nurse workforce. JAMA 1996;276:1487-93.

23. Institute of medicine committee on the robert wood johnson foundation initiative on the future of nursing atIoM. In: The future of nursing: leading change, advancing health. Washington, DC: National Academies Press; 2011.

24. Coffman J, Chan K, Bates T. Profile of the licensed practical nurse/licensed vocational nurse workforce, 2008 and 2013. San Francisco, CA: UCSF Health Workforce Research Center on Long-Term Care; 2015.

25. Freburger JK, Li D, Fraher EP. Community use of physical and occupational therapy after stroke and risk of hospital readmission. Arch Phys Med Rehabil 2018;99:26-34.e25.

26. Sandberg SF, Erikson C, Yunker ED. Evolving health workforce roles in accountable care organizations. Am J Accountable Care 2017;5:9-14.

27. Peikes DN, Reid RJ, Day TJ, et al. Staffing patterns of primary care practices in the comprehensive primary care initiative. Ann Fam Med 2014; 12:142-9.

28. Aita V, Dodendorf DM, Lebsack JA, Tallia AF, Crabtree BF. Patient care staffing patterns and roles in community-based family practices. J Fam Pract 2001;50:889.

29. Leach B, Morgan P, Strand de Oliveira J, Hull S, Østbye T, Everett C. Primary care multidisciplinary teams in practice: a qualitative study. BMC Fam Pract 2017;18:115.

30. Frogner BK, Fraher EP, Spetz J, et al. Modernizing scope-of-practice regulations-Time to prioritize patients. N Engl J Med 2020;382:591-3.

31. Ghorob A, Bodenheimer T. Share the Care $^{\mathrm{TM}}$ : building teams in primary care practices. J Am Board Fam Med 2012;25:143-5.

32. Smith CD, Balatbat C, Corbridge $\mathrm{S}$, et al. Implementing optimal team-based care to reduce clinician burnout. Washington, DC: National Academy of Medicine; 2018.

33. Kung A, Cheung T, Knox M, et al. Capacity to address social needs affects primary care clinician burnout. Ann Fam Med 2019;17:487-94.

34. Helfrich CD, Dolan ED, Simonetti J, et al. Elements of team-based care in a patient-centered medical home are associated with lower burnout among VA primary care employees. J Gen Intern Med 2014;29:659-66 (Suppl 2).

35. Edwards ST, Helfrich CD, Grembowski D, et al. Task delegation and burnout trade-offs among primary care providers and nurses in Veterans Affairs patient aligned care teams (VA PACTs). J Am Board Fam Med 2018;31:83-93. 